\title{
Statistical modeling of interannual shoreline change driven by North Atlantic climate variability spanning 2000-2014 in the Bay of Biscay
}

\author{
A. Robinet ${ }^{1,2,3}$ (D) B. Castelle $^{2,3} \cdot$ D. Idier $^{1} \cdot$ G. Le Cozannet $^{1} \cdot$ M. Déqué ${ }^{4} \cdot$ E. Charles $^{5}$
}

Received: 6 May 2016 / Accepted: 2 August 2016/Published online: 9 August 2016

(C) The Author(s) 2016. This article is published with open access at Springerlink.com

\begin{abstract}
Modeling studies addressing daily to interannual coastal evolution typically relate shoreline change with waves, currents and sediment transport through complex processes and feedbacks. For wave-dominated environments, the main driver (waves) is controlled by the regional atmospheric circulation. Here a simple weather regime-driven shoreline model is developed for a 15-year shoreline dataset (2000-2014) collected at Truc Vert beach, Bay of Biscay, SW France. In all, 16 weather regimes (four per season) are considered. The centroids and occurrences are computed using the ERA-40 and ERA-Interim reanalyses, applying $k$-means and EOF methods to the anomalies of the 500-hPa geopotential height over the North Atlantic Basin. The weather regime-driven shoreline model explains $70 \%$ of the observed interannual shoreline variability. The application of a proven wavedriven equilibrium shoreline model to the same period shows that both models have similar skills at the interannual scale. Relation between the weather regimes and the wave climate in the Bay of Biscay is investigated and the primary weather regimes impacting shoreline change are identified. For instance, the winter zonal regime characterized by a strengthening of the pressure gradient between the Iceland low and the Azores high is associated with high-energy wave conditions
\end{abstract}

A. Robinet

a.robinet@brgm.fr

1 BRGM, DRP/R3C, 45100 Orléans, France

2 CNRS, UMR 5805 EPOC, Pessac, France

3 Univ. Bordeaux, UMR 5805 EPOC, Pessac, France

4 CNRM/GAME, Météo-France, Toulouse, France

5 CNRS, CNES, IRD, Université Paul Sabatier, UMR 5566 LEGOS, Toulouse, France and is found to drive an increase in the shoreline erosion rate. The study demonstrates the predictability of interannual shoreline change from a limited number of weather regimes, which opens new perspectives for shoreline change modeling and encourages long-term shoreline monitoring programs.

\section{Introduction}

Sandy coasts are complex environments that are under increasing threat posed by anthropogenic pressures and climate change. Shoreline change is governed by myriad nonlinear physical processes interacting through complex feedbacks covering a wide range of spatial and temporal scales (Stive et al. 2002), challenging model developments. Although several complex process-based morphodynamic models have been developed in recent decades, simulations at large temporal scales, i.e., years, are still hardly reliable. Shoreline evolution on timescales from hours (cf. storms) to years has recently been simulated with fair skill using wave-driven empirical equilibrium-based models (e.g., Davidson and Turner 2009; Yates et al. 2009; Davidson et al. 2013; Castelle et al. 2014; Splinter et al. 2014a). These models can also reproduce the interannual shoreline variability that sometimes exceeds the seasonal variability (e.g., Castelle et al. 2014). However, model skills strongly depend on the availability and quality of wave data. The characteristics of waves reaching the coast depend strongly on remote surface atmospheric circulation (e.g., Bacon and Carter 1993; Young 1999; Woolf et al. 2002; Le Cozannet et al. 2011; Charles et al. 2012a; Martínez-Asensio et al. 2016). Because waves are the primary driver of shoreline change along most coastlines, interannual shoreline variability is expected to be related to interannual large-scale atmospheric dynamics. Therefore, directly using atmospheric conditions as inputs in shoreline models appears 
as an appealing approach. This reduced-complexity strategy may also implicitly account for other drivers such as mean water level fluctuations (Ruggiero et al. 2001; Serafin and Ruggiero 2014).

Using a simple approach, Kuriyama et al. (2012) revealed that about $45 \%$ of the interannual shoreline variability measured at a NW Pacific Ocean beach can be attributed to largescale climate fluctuations described through a combination of teleconnection pattern indices. Barnard et al. (2015) recently gave new evidence that large-scale atmospheric circulation patterns control unusual, local storm-driven shoreline change around the Pacific Basin, with enhanced erosion along the NW American coast and the SE Australian coast caused by extreme El Niño and La Niña, respectively. Studies focusing on NE Atlantic sandy coasts and climate variability have already highlighted the existence of a relationship between the North Atlantic Oscillation teleconnection (NAO) and the beach sand bar states (e.g., Masselink et al. 2014) or alongshore sediment transport (e.g., Silva et al. 2012; Idier et al. 2013). However, none of these studies addresses the potential link between the large-scale atmospheric circulation and shoreline variability. In addition, these studies used teleconnection pattern indices to characterize the largescale atmospheric circulation, as they are freely available online and easy to use. However, it is also possible to describe large-scale atmospheric circulation and its variability by so-called weather regimes.

Weather regimes are recurrent and persistent atmospheric circulation patterns. They are usually identified by cluster analysis (Michelangeli et al. 1995) applied to daily fields of mean sea-level pressure or geopotential height (at a given pressure level) taken over an area of interest. Using this approach, the North Atlantic synoptic circulation can be accurately characterized, as atmospheric data located over the oceanic basin only are used for the weather regime computation (Cassou et al. 2004; Barrier et al. 2013, 2014).

In this paper, a simple weather regime-driven shoreline model is implemented to investigate shoreline interannual variability at Truc Vert beach, Bay of Biscay, SW France. A set of 16 seasonal weather regimes (four per season) is computed for the North Atlantic Basin and the shoreline model is tested against a shoreline dataset covering a 15-year period from 2000 to 2014 . The relation between weather regimes, waves and shoreline evolution, as well as the model skills are discussed.

\section{Physical setting}

Truc Vert is a meso-macrotidal double-barred open beach backed by high and wide coastal dunes (Fig. 1a, b). The sediment consists of fine to medium sand with a mean grain size of about $0.35-0.40 \mathrm{~mm}$. Truc Vert is exposed to high-energy, seasonally modulated waves generated over the North Atlantic Ocean with a mean significant wave height $H_{\mathrm{s}}$ of $1.7 \mathrm{~m}$, a mean peak wave period of $10.3 \mathrm{~s}$ and a dominant WNW direction (Castelle et al. 2015). Summer is characterized by the dominance of NW short waves whereas longer and larger waves coming from the WNW prevail in winter. $H_{\mathrm{s}}$ can episodically exceed $8 \mathrm{~m}$ during severe winter storms with a peak wave period often larger than $15 \mathrm{~s}$ (Castelle et al. 2015). This is illustrated in Fig. 2e based on a time series of 3-hourly $H_{\mathrm{s}}$ offshore of Truc Vert beach with the superimposed 90-day moving average over the period 2000-2014 using the wave data described in Castelle et al. (2014).

The North Atlantic atmospheric circulation is characterized by westward-tracking extra-tropical low-pressure systems over the North Atlantic Ocean, which is regularly interrupted by broadening of high-pressure systems. In winter, the North Atlantic atmospheric variability is found to be accurately characterized on a daily basis through the so-called weather regime paradigm (see, for example, Barrier et al. 2014). Four welldefined circulation patterns inherent to the atmospheric dynamics over the North Atlantic Ocean are usually identified (Vautard 1990; Cassou et al. 2004). The zonal regime (ZO) is characterized by a strengthening of the pressure gradient between the Iceland low and the Azores high. The Greenland anticyclone (GA) exhibits an opposite structure with a gradient lowering. $\mathrm{ZO}$ and GA correspond to the positive and negative phase of the North Atlantic Oscillation $(\mathrm{NAO}+$ and NAO-), respectively (Cassou et al. 2011). The blocking regime (BL) refers to a situation in which a persistent anticyclone is located over northern Europe and Scandinavia. The Atlantic ridge (AR) is associated with a broadening of the Azores high, and is very close to the negative phase of the East Atlantic pattern (EA; Barnston and Livezey 1987; Cassou et al. 2011). Intensification of the latitudinal pressure gradient over the North Atlantic Ocean typically results in stronger westerly winds promoting energetic waves that propagate toward Truc Vert, whereas persistence of anticyclonic conditions over the North Atlantic Basin results in smaller waves. However, the overall relations between these basinscale weather regimes and the local wave and shoreline dynamics at Truc Vert have not yet been investigated. This is addressed in this study.

\section{Materials and methods}

\section{Shoreline data}

Two topographic datasets were gathered to produce a shoreline dataset that covers a 15 -year study period from 2000 to 2014. From March 2000 to March 2005, single beach profiles were collected through various means (e.g., theodolite, DGPS). From April 2005 to December 2014, with a 1-year 


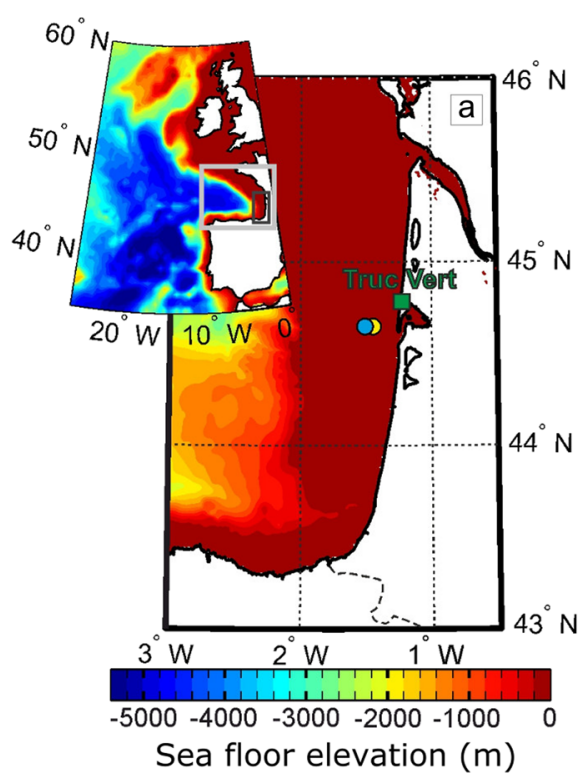

Fig. 1 a Truc Vert beach location (green square) in the Bay of Biscay (gray box), and buoy and wave model grid point used to produce the wave hindcast (blue and yellow dots, respectively). b Aerial view of Truc Vert beach. c Alongshore-averaged beach profiles surveyed at Truc Vert beach from April 2005 to April 2013 (gray curves) and time-

gap in 2008, 2-4 week sampled topographic surveys were performed at Truc Vert at spring low tide using a centimeteraccuracy Trimble 5700 DGPS. The alongshore coverage increased over the years from about $350-750 \mathrm{~m}$ in early 2009 to about $1,500 \mathrm{~m}$ in October 2012 onward. The topographic surveys were averaged alongshore to derive a mean beach profile (for more details, see Castelle et al. 2014, 2015 and Splinter et al. 2014a). Figure 1c shows the superimposed mean profiles surveyed from 2005 to 2013 where the elevation is given with respect to the local mean sea level, highlighting the large vertical and cross-shore variability.

The shoreline proxy explaining the largest amount of the total beach volume variability was chosen. The total beach volume was computed by integrating all positive elevations above the local mean sea level up to the backbeach where the topographic elevation remains approximately constant over time, with the total volume at the start of the survey period set to 0 . The vertical distribution of the correlation coefficient between the shoreline proxy and the beach volume is reported in Fig. 1d for the 2005-2013 period. The best correlations are obtained for elevations ranging from 1 to $2 \mathrm{~m}$ above mean sea level, which approximately corresponds to the mean high water level for neap and spring tides, respectively (Fig. 1c, d). The mean high water level shoreline proxy $(1.5 \mathrm{~m}$ above the local mean sea level) is used here, which agrees with previous shoreline modeling studies at Truc Vert beach (Castelle et al. 2014; Splinter et al. 2014a).

Figure $2 \mathrm{f}$ shows the time series of shoreline position at Truc Vert combining the whole dataset. Error bars indicate the alongshore standard deviation of the 1.5-m iso-contour, which b
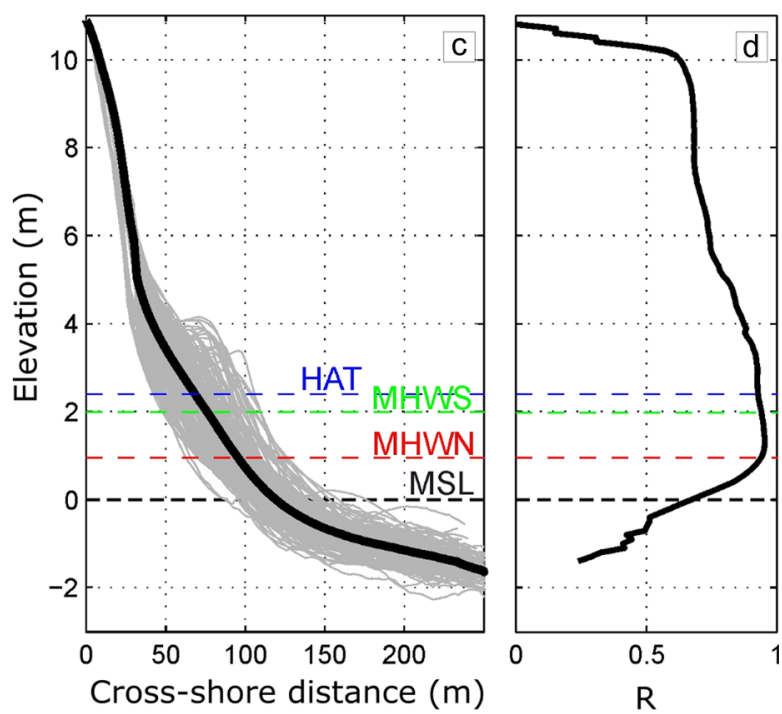

averaged mean profile (black curve). d Vertical distribution of correlation coefficient between shoreline position and total beach volume. HAT, MHWS, MHWN and MSL indicate highest astronomical tide, mean high water spring, mean high water neap and mean sea level, respectively

is a measure of beach three-dimensionality, with a mean error bar length of $7.9 \mathrm{~m}$. The large variability in error bars starting in 2005 reflects the strong beach three-dimensional variability throughout the years. The shoreline positions prior to April 2005 are also included, despite their low accuracy blurring the seasonal variability. Nonetheless, this supplementary dataset further highlights a striking interannual shoreline signal within the entire 2000-2014 period. The seasonal cycles are generally characterized by a succession of accretional and erosional periods centered on the summer and winter, respectively. Spring and fall are both transition periods that can be either accretional or erosional, although a slight mean accretion trend is found for both seasons. The cross-shore amplitude of the interannual variability is 30 to $40 \mathrm{~m}$, which is similar to the amplitude of the seasonal cycle. The whole dataset appears to capture two full cycles of interannual variability (Fig. 2f), with three shoreline minima (erosion) in approximately 2001, 2009 and 2014, and two maxima (accretion) in approximately 2005 and 2012 .

\section{Weather regime computation}

Assessment of the North Atlantic climate variability is based on two global atmospheric reanalyses produced by the European Centre for Medium-Range Weather Forecasts (ECMWF). The ERA-40 reanalysis (Uppala et al. 2005) is used to compute the weather regime centroids and their daily occurrence for the 1958-2001 period. As the ERA-40 reanalysis does not cover the 2000-2014 study period, the ongoing ERA-Interim reanalysis (Dee et al. 2011), which started in 1979, is used to 

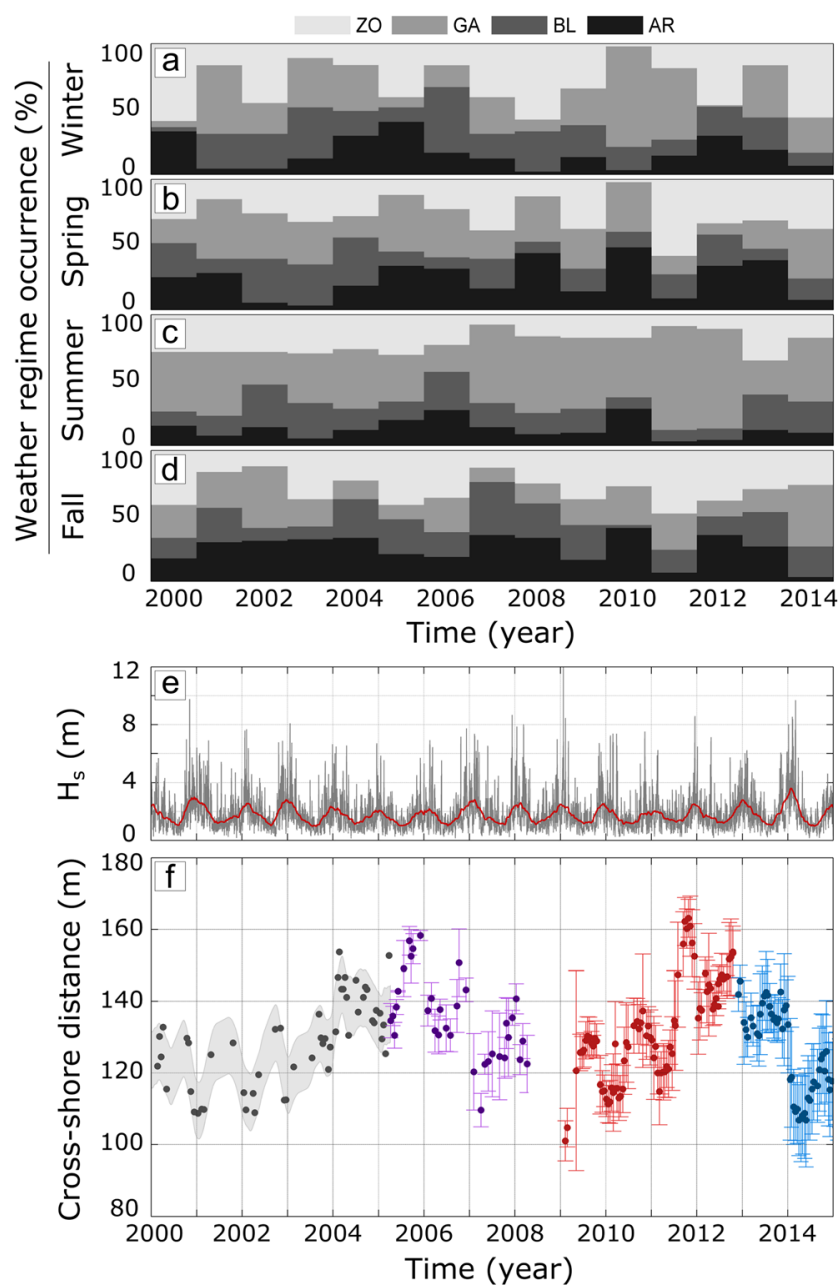

Fig. 2 a-d Seasonal weather regime occurrence in percentage derived from the ERA-Interim reanalysis from winter 2000 to fall 2014. ZO, GA, $B L$ and ARZonal, Greenland anticyclone, blocking and Atlantic ridge regimes, respectively. e Significant wave height $H_{\mathrm{s}}$ and 90-day moving average (red line). $\mathbf{f}$ Measured shoreline position using the mean high water level proxy at $z=1.5 \mathrm{~m}$. Gray dots Shoreline positions calculated using single beach profiles, colored dots shoreline positions calculated by averaging the position of the mean high water level iso-contour over an alongshore distance of approx. $350 \mathrm{~m}$ (purple), $750 \mathrm{~m}$ (red) and 1,500 m (blue). Error bars Associated cross-shore standard deviation. Gray area 90-day moving average \pm mean cross-shore standard deviation

compute the daily occurrence of the weather regimes for this study period, assuming the quasi-stationarity of the weather regimes (Michelangeli et al. 1995; Cassou et al. 2004).

Because of a strong seasonal modulation of the North Atlantic atmospheric circulation, and in turn of the wave energy, weather regimes are computed by meteorological season: winter (December, January, and February), spring (March, April and May), summer (June, July and August) and fall (September, October and November). The weather regime centroids are computed as in Sanchez-Gomez et al. (2009), that is, by using the anomaly maps of the $500-\mathrm{hPa}$ geopotential height (Z500) over the North Atlantic Basin $\left(90^{\circ} \mathrm{W}-30^{\circ} \mathrm{E}, 20-80^{\circ} \mathrm{N}\right)$ for the $1958-2001$ period. The classification into weather regimes is performed by applying the $k$-means partition algorithm to the data after reducing the number of degrees of freedom using an EOF decomposition (Michelangeli et al. 1995). Only the first 15 principal components are retained, which explains about $90 \%$ of the total variance. For each season the optimal Z500 anomaly field partitioning is carried out with four clusters. Once the centroids are defined, for both reanalyses the weather regime occurrence is computed on a daily basis, such that each day is associated to one of the 16 weather regimes. The similarity criterion is based on the Euclidian distance between the daily Z500 anomaly map and the weather regime centroids. Finally, yearly seasonal occurrence is computed to provide the time series of seasonal weather regime occurrence. For each season of each year, the cumulative occurrence of the four seasonal weather regimes always equals $100 \%$ of the time, meaning that the time series are interdependent within each season.

\section{Weather regime impact on wave climate}

At Truc Vert and along many other waved-dominated sandy beaches, waves are the primary driver of shoreline change. To support the development of a shoreline evolution model driven by weather regimes, the relation between the weather regimes and the local wave climate is explored on seasonal timescales. This relation is assessed by computing correlation maps between time series of seasonal weather regime occurrence derived from the ERA-40 reanalysis (1958-2001) and seasonal wave parameter anomalies computed over the Bay of Biscay (bordered by the N Spanish and W French coasts, see Fig. 1) using the BoBWA-10kH wave hindcast (Charles et al. 2012b). The wave parameters used are $H_{\mathrm{s}}$, the mean wave period and the peak wave direction. Because waves are essentially wind-generated, to provide insights into possible relations between weather regimes and waves the seasonal surface wind modification over the North Atlantic Ocean is assessed by computing and analyzing the $10-\mathrm{m}$ seasonal mean wind maps and the $10-\mathrm{m}$ wind mean composites corresponding to the 16 weather regimes.

\section{Statistical weather regime-driven shoreline model}

To investigate the predictability of the interannual shoreline variability, a simple model linking seasonal shoreline change and weather regime occurrence is developed. A limited number of weather regimes is used in comparison with existing studies downscaling wave climatology from atmospheric data (e.g., Camus et al. 2014; Laugel et al. 2014). Here, using a small number of well-defined circulation patterns is a necessary requirement both to ease interpretation and to achieve a robust statistical model setup as a higher number of circulation patterns would require a longer shoreline dataset. The model 
considers the shoreline position as an auto-regressive process (i.e., it depends linearly on its own previous values) and assumes that, for a given season, the rate of shoreline change is controlled by a linear combination of individual weather regime occurrence. With these assumptions, the simulated shoreline position $x_{\bmod }$ is calculated on the first day of each season:

$x_{\text {mod }}(t+\Delta t)=x_{\text {mod }}(t)+u_{\text {mod }}(t) \times \Delta t$

where $t$ is the time, $\Delta t$ is the seasonal time step and equals the duration of that season in days (between $t$ and $t+\Delta t$ ), and $u_{\text {mod }}$ is the weather regime-based estimate of shoreline change rate during that season. $u_{\text {mod }}$ is obtained from the following season-dependent equation:

$u$ mod $(t)=a_{\text {season }}+\sum_{\mathrm{i}=1}^{3} b_{\mathrm{i}, \text { season }} \mathrm{WR}_{\mathrm{i}}(t)$

where $\mathrm{WR}_{\mathrm{i}}$ is the occurrence value of the $i$ th weather regime during a given season, $b_{\mathrm{i} \text {,season }}$ is the coefficient associated with $\mathrm{WR}_{\mathrm{i}}$ and is season-dependent, and $a_{\text {season }}$ is a season-dependent constant. Values of $a_{\text {season }}$ and $b_{\mathrm{i}, \text { season }}$ are calibrated for each season by performing multiple-linear regression between the seasonal weather regime occurrence and the corresponding time series of measured seasonal shoreline change rate over the period spanning April 2005 to December 2014 (hereafter called the calibration period). For each season only three out of the four time series of seasonal weather regime occurrence are used as these time series are interdependent (see Weather regime computation subsection). Indeed, the sum of the occurrence of the four weather regimes is $100 \%$, such that the occurrence of the fourth regime can be deduced from the occurrence of the three other ones. Using the four time series would therefore add redundant data in the multiple-linear regressions. A preliminary analysis indicates that changing the three weather regimes causes no change to the model output.

Both the measured and simulated shoreline time series are detrended with a linear fit to remove the long-term trend, as this study aims at investigating the interannual variability of shoreline change. The model skill is assessed in terms of the root-mean-square error (RMSE) and coefficient of determination $\left(R^{2}\right)$. Since the topographic surveys were performed at irregular intervals and depending on tide range, there is no measurement concurrent with the model output. To assess model skill, each simulated shoreline position is associated with the average of the measured shoreline positions at \pm 15 days of the simulated position. As a last processing step, the measured and simulated shoreline position time series are linearly interpolated and further low-pass filtered with a 2-year cutoff frequency to focus on the interannual shoreline variability.

\section{Results}

\section{Weather regimes and wave climate}

The four computed winter centroids (Fig. 3a, e, i, m) are very similar in pattern with those described in the literature (Vautard 1990; Cassou et al. 2004) and introduced in the Physical setting section. For the other seasons, the centroids are characterized by similar anomaly patterns, although some significant shifts of the Z500 anomaly position and magnitude are detected, especially during fall (Fig. 3). For clarity, each centroid is denoted by the name of the most similar winter centroid.

The most significant correlation maps are obtained for the winter and summer seasons (Figs. 4 and 5, respectively). For both seasons, the seasonal wave characteristics off the SW French Atlantic coast appear to be strongly related with the weather regimes. High occurrence of winter and summer ZO is associated with an increase in $H_{\mathrm{s}}$ and mean wave period (Figs. $4 \mathrm{a}, \mathrm{b}$ and $5 \mathrm{a}, \mathrm{b}$ ). During winter and summer, high occurrence of GA is associated with an anticlockwise rotation of the peak wave direction (Figs. $4 \mathrm{f}$ and $5 \mathrm{f}$ ). In addition, high occurrence of winter GA decreases the mean wave period (Fig. 4e) whereas high occurrence of summer GA leads to an increase in $H_{\mathrm{s}}$ (Fig. 5a). High occurrence of winter and summer BL is associated with a slight decrease in $H_{\mathrm{s}}$ (Figs. $4 \mathrm{~g}$ and $5 \mathrm{~g}$ ). Finally, high occurrence of winter and summer AR drives a clockwise rotation of the peak wave direction (Figs. 41 and 51) along with a decrease in $H_{\mathrm{s}}$, which is more pronounced in summer (Figs. $4 \mathrm{j}$ and $5 \mathrm{j}$ ).

Figure 6 reveals that the weather regimes appear to strongly modulate the surface wind patterns over the North Atlantic Basin. While some weather regimes are associated with a strong reinforcement of the mean surface circulation at various locations (e.g., ZO), others lead to a decrease in wind magnitude and drive significant change in the mean surface wind direction (e.g., AR).

The time series of seasonal weather regime occurrence from winter 2000 to fall 2014 and derived from the ERAInterim reanalysis are shown in Fig. 2a-d. The North Atlantic Ocean atmospheric circulation displays a strong variability on both seasonal and interannual timescales.

\section{Model results}

The simulated shoreline position in Fig. 7a indicates that the seasonal cycles over the calibration period are well captured by the model, although the cross-shore excursion is slightly underestimated. Over this period, the RMSE and $R^{2}$ calculated between the measured and simulated shoreline positions are $8.6 \mathrm{~m}$ and 0.61 , respectively. Prior to April 2005, the seasonal cycles are still reproduced, with the low-accuracy data over this period preventing relevant model skill assessment. 

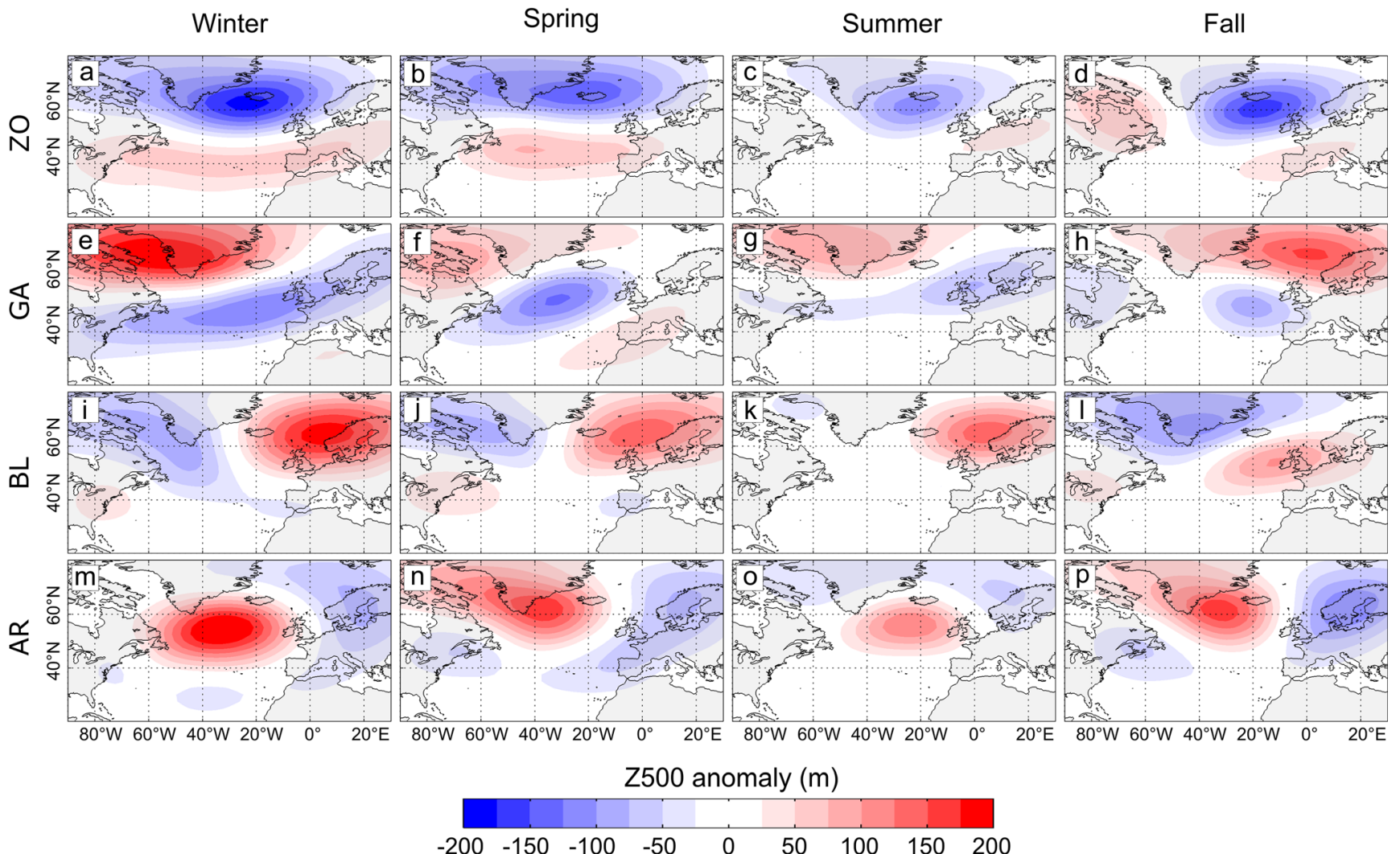

$-200-150 \quad-100 \quad-50$

Fig. 3 North Atlantic weather regime centroids for winter (December, January, February), spring (March, April, May), summer (June, July, August) and fall (September, October, November). The centroids are computed from the anomaly maps of the $500-\mathrm{hPa}$ geopotential height

Figure $7 \mathrm{~b}$ shows the interannual signal contained in both time series, highlighting that the model reproduces the interannual variability from April 2005 to December 2014 with excellent skill (RMSE and $R^{2}$ of $5.0 \mathrm{~m}$ and 0.93 , respectively). From 2000 to the end of 2004, the overall slow accretion trend in the measurements is well captured by the model, although there is a substantial shift between the two signals. Therefore, the interannual variability is also well reproduced over the entire period, with a RMSE of $5.9 \mathrm{~m}$ and $R^{2}$ of 0.70 .

\section{Discussion}

\section{Weather regimes, wave climate and shoreline change}

A detailed inspection of Fig. 6 shows how the weather regimes can affect the wave climate in the Bay of Biscay. The surface wind modifications induced by the weather regimes have a profound impact on wave generation in the North Atlantic Ocean and, in turn, on the waves reaching the Bay of Biscay. Figure $6 \mathrm{a}-\mathrm{d}$ indicates that during all seasons $\mathrm{ZO}$ occurrence is characterized by above average surface winds blowing from the $\mathrm{W}$ to $\mathrm{E}$, such that $\mathrm{ZO}$ occurrence should allow energetic swells to develop and propagate toward $\mathrm{W}$ over the North Atlantic Basin obtained from the ERA-40 reanalysis. $Z O, G A, B L$ and $A R$ Zonal, Greenland anticyclone, blocking and Atlantic ridge regimes, respectively

European coasts, which agrees with the results found in Fig. 4a, b and Fig. 5a, b. On the contrary, Fig. 6m-p shows that AR occurrence is characterized by a strong reduction or even a disappearance of the $\mathrm{W}$ wind component over the central part of North Atlantic Ocean and by an increase in winds blowing from the N-NW over the Bay of Biscay. These combined effects should limit swell occurrence and favor the formation of NW seas in the Bay of Biscay, explaining the wave patterns depicted in Fig. $4 \mathrm{j}-1$ and Fig. $5 \mathrm{j}-1$. Figure $6 \mathrm{e}$, g reveals that the maximal zonal surface circulation is shifted southward for winter and summer GA occurrence, giving a plausible reason for the anticlockwise rotation of wave direction observed in Fig. 4f and Fig. 5f. The interpretation of the wind composites associated with BL occurrence (Fig. 6i-1) is more difficult. However, the slight decrease in $H_{\mathrm{s}}$ observed in winter and summer (Figs. $4 \mathrm{~g}$ and $5 \mathrm{~g}$ ) could be related to the smaller distance over which westerly surface winds blow in the middle of the North Atlantic Ocean.

To estimate weather-regime impact on shoreline change on seasonal timescales, correlation coefficients $(R)$ between the time series of the seasonal weather regime occurrence and seasonal shoreline change rate are calculated for the 2005 2014 calibration period. A positive value indicates that the 


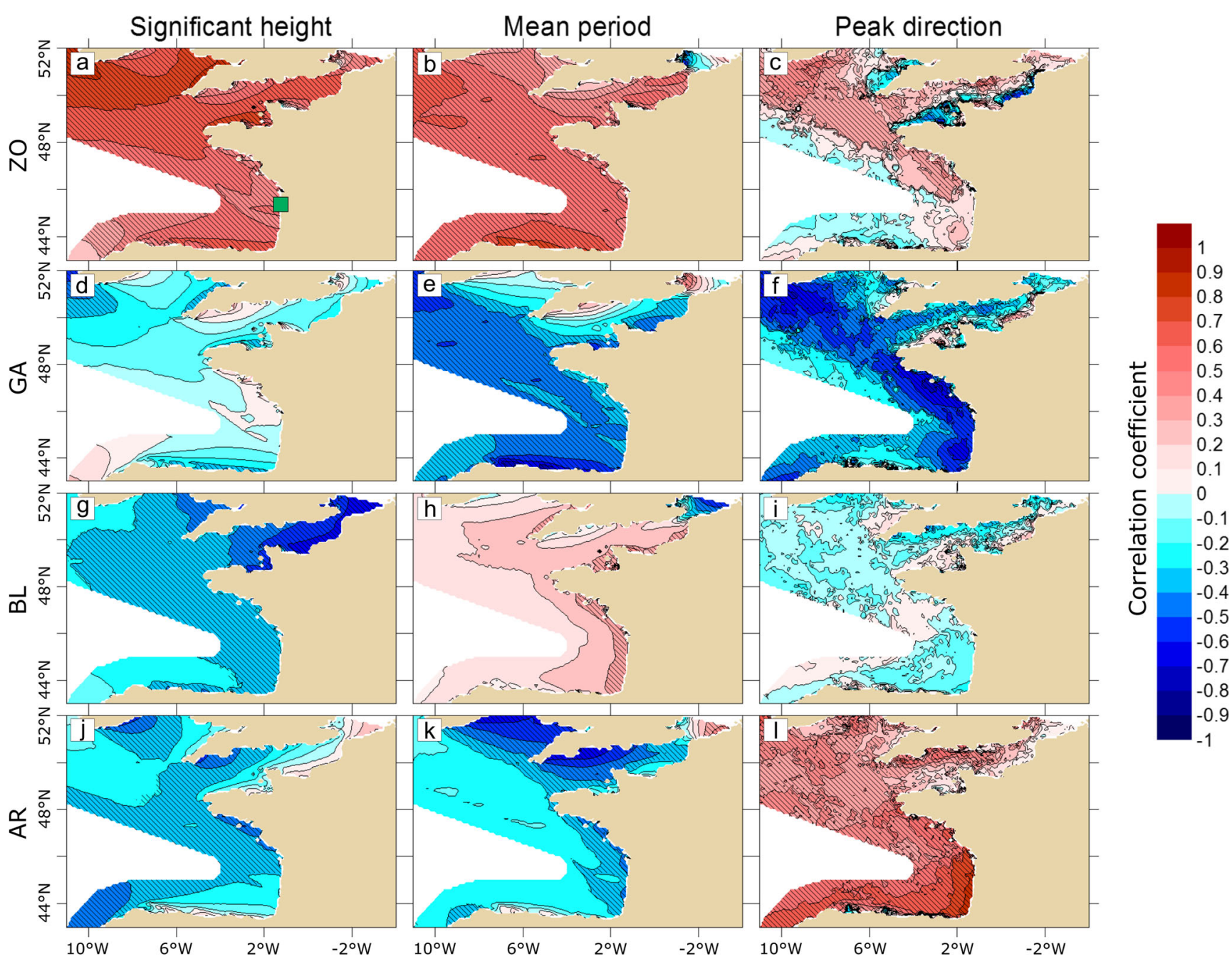

Fig. 4 Correlation maps computed between the winter weather regime occurrence derived from the ERA-40 reanalysis and wave characteristic anomalies calculated from the BoBWA-10kH wave hindcast in the Bay of Biscay for the 1958-2001 period. A positive anomaly in peak direction

corresponds to a clockwise rotation. Hatched areas Significant correlations at $95 \% . Z O, G A, B L$ and $A R$ Zonal, Greenland anticyclone, blocking and Atlantic ridge regimes, respectively. Green square (upper left) Truc Vert beach location

corresponding weather regime reduces the seasonal erosion trend or amplifies the seasonal accretion trend. Most of the obtained correlation values are not statistically significant. However, four seasonal weather regimes have significant correlation with $p$-values ranging from 0.05 to 0.15 : in winter, $\mathrm{ZO}$ high occurrence increases erosion rate $(R=-0.56)$; in spring, AR high occurrence is associated with a decreased accretion rate $(R=-0.60)$; in summer, GA and $\mathrm{BL}$ high occurrences lead to an increase $(R=0.61)$ and a decrease in accretion rate $(R=-$ $0.67)$, respectively. It has been proven on many wavedominated coasts that shoreline change rate is proportional to the incident wave energy, and the energy disequilibrium between this energy and the equilibrium energy for which the coast is stable (Davidson and Turner 2009; Yates et al. 2009). Thus, the statistically significant relationships identified here may be related to weather regime-driven modulation of incoming wave energy. Change in water level induced by weather regime-driven variations of sea-level pressure
(Barrier et al. 2013) and/or onshore winds (Ullmann and Moron 2008; Ullmann and Monbaliu 2010) may also impact shoreline change as storm wave events coinciding with higher water levels result in higher rates of erosion (Ruggiero et al. 2001; Serafin and Ruggiero 2014). However, this was not verified here as it is beyond the scope of this study.

According to the results of the correlation maps (Fig. 4), in winter, only high occurrence of $\mathrm{ZO}$ is associated with larger and longer waves offshore of Truc Vert, which is expected to increase beach erosion. During summer, high occurrence of GA is associated with larger waves and an anticlockwise rotation of the peak wave direction (Fig. 5d, f), allowing the wave incidence to be closer to shore normal. Onshore wavedriven sediment transport requires a minimal amount of incident wave energy to move the eroded sand back on the beach. It is hypothesized that, for the summer GA weather regime, slightly above average $H_{\mathrm{s}}$ favors beach recovery at Truc Vert. The results also reveal that, during summer, high occurrence 

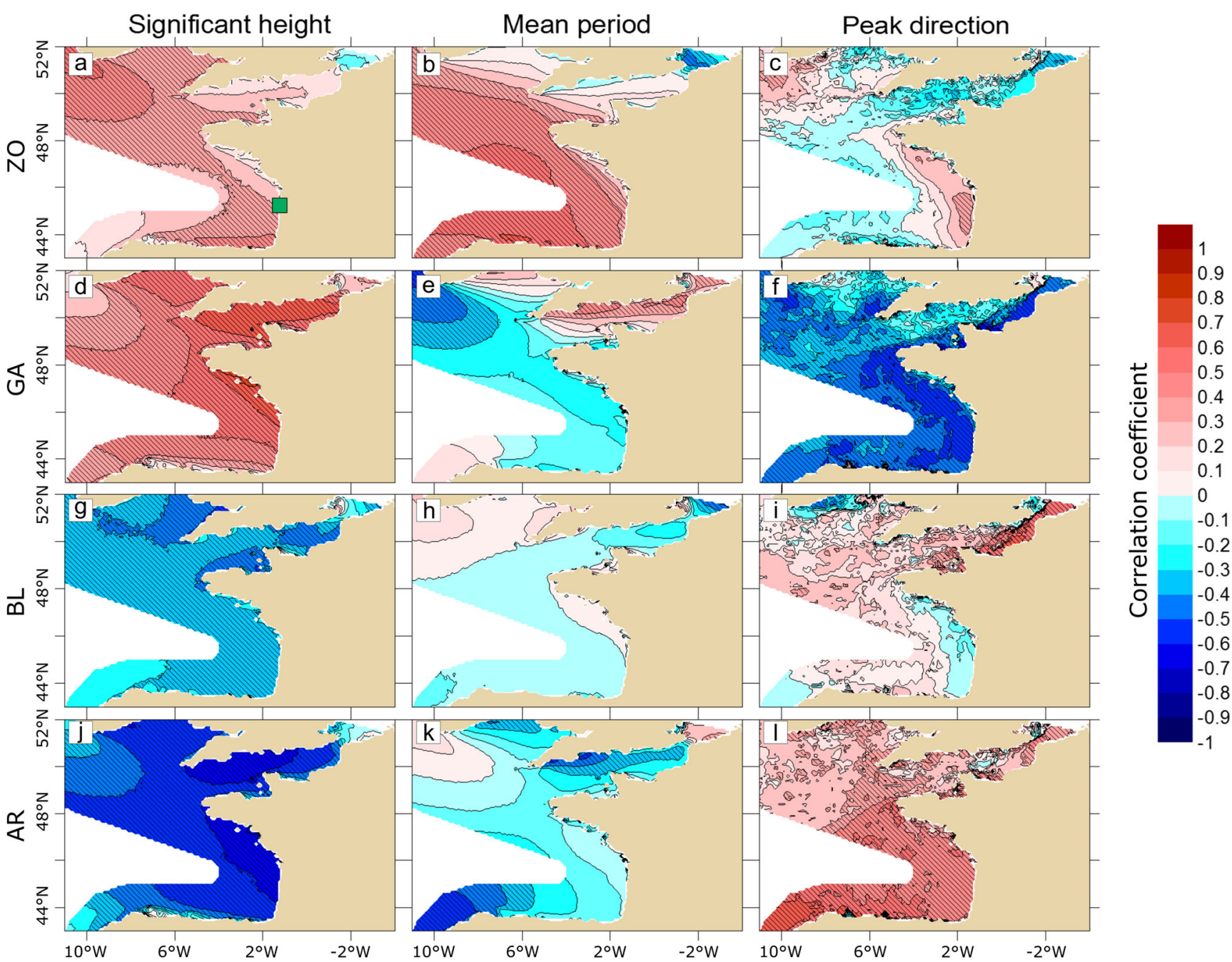

Fig. 5 Same as Fig. 4 for summer
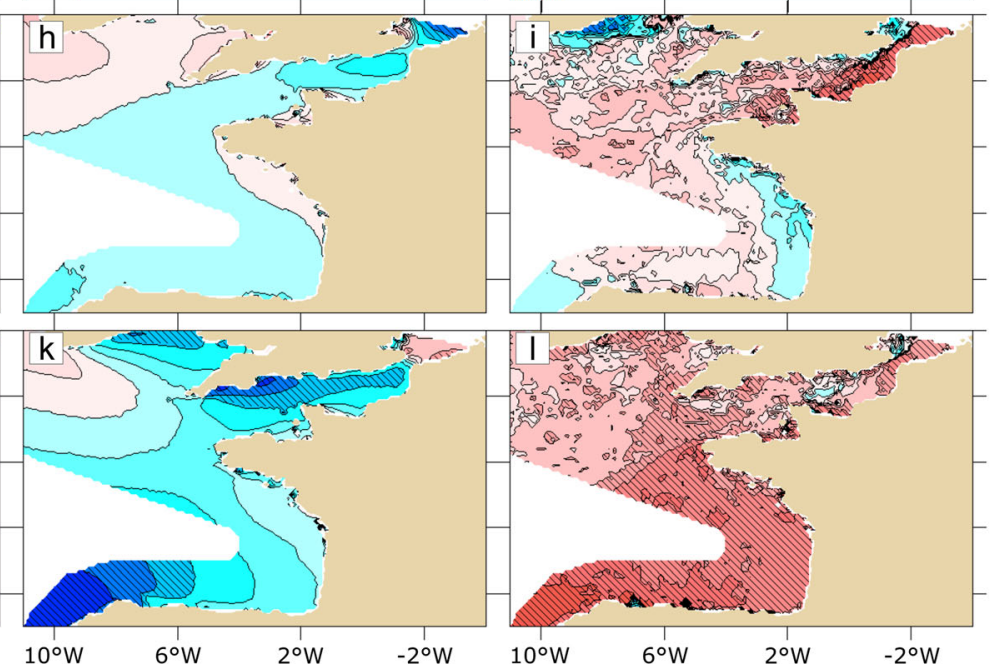

of $\mathrm{BL}$ is associated with smaller waves (Fig. $5 \mathrm{~g}$ ) and $\mathrm{BL}$ occurrence appears to be anti-correlated to GA occurrence in summer (Fig. 2c). By reducing the occurrence of GA and by causing lower energy conditions, BL high occurrence is expected to slow down beach recovery at Truc Vert. Figure 6n shows that spring AR is characterized by nearly no wind circulation over the central part of the North Atlantic Ocean, and light winds blowing from the $\mathrm{N}$ over the Bay of Biscay resulting in very low energy conditions. High occurrence of $\mathrm{AR}$ in spring is therefore associated with low incoming wave energy at Truc Vert, which limits post-winter beach recovery.

Shoreline change also strongly depends on antecedent wave conditions (Wright and Short 1984; Davidson et al. 2013; Splinter et al. 2014a) and storm event chronology (Splinter et al. 2014b). Therefore, investigating the individual contribution of the weather regimes to shoreline change on seasonal timescales could be improved by accounting for a "memory" effect. However, the present shoreline dataset spans too short a duration to perform such an analysis.

\section{Weather regime-driven shoreline model}

To test the ability of the model to simulate the relationship between the seasonal weather regime occurrence and the interannual shoreline variability, randomization tests are performed. Model input data were replaced by a dataset of 16 random signals following a uniform law with mean and standard deviation similar to the time series of weather regime occurrence. Over 1,000 simulations were performed on random inputs, and the results indicate that the probability to increase model skill is less than $1 \%$. This confirms that the model is not over-calibrated and that there is a physical relation between the combination and succession of the seasonal weather regime occurrence and the interannual shoreline dynamics. According to the above results, large-scale atmospheric fluctuations over the North Atlantic Ocean, described here through the weather regime paradigm, can explain up to $70 \%$ of the interannual shoreline variability measured at Truc Vert beach between 2000 and 2014. However, the model 

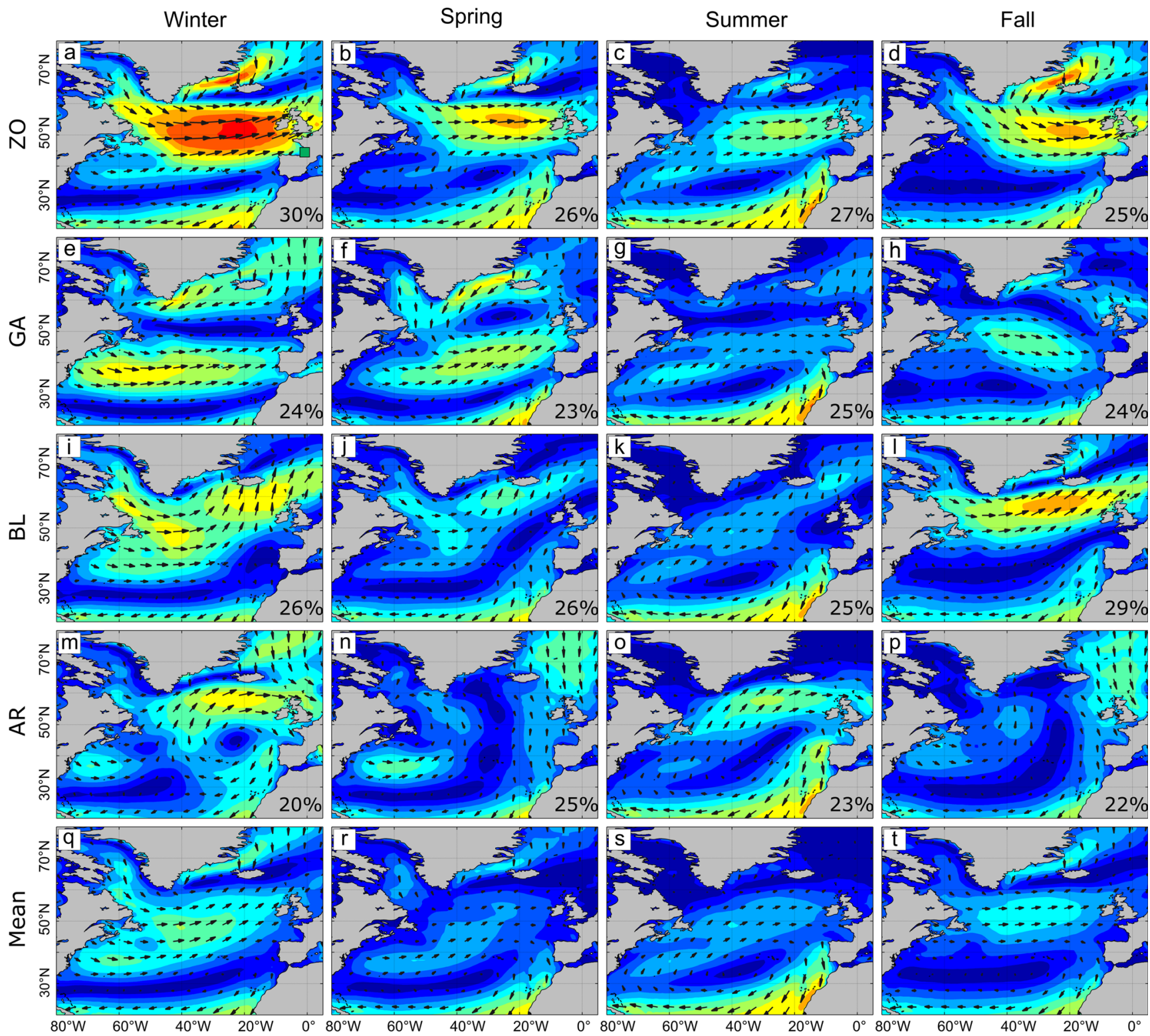

Wind speed $(\mathrm{m} / \mathrm{s})$

\section{$\begin{array}{lllllllllllll}0 & 1 & 2 & 3 & 4 & 5 & 6 & 7 & 8 & 9 & 10 & 11 & 12\end{array}$}

Fig. 6 a-p Mean seasonal wind composites for each weather regime and q-t mean seasonal wind fields derived from ERA-40 10-m wind fields of the 1958-2001 period for winter (December, January, February), spring (March, April, May), summer (June, July, August) and fall (September,
October, November). Percentages Mean seasonal weather regime occurrence. ZO, GA, BL and AR Zonal, Greenland anticyclone, blocking and Atlantic ridge regimes, respectively. Green square (upper left) Truc Vert beach location underestimates both maxima for erosion and accretion because it solves shoreline change on a seasonal timescale. This is a major limitation compared to equilibrium shoreline models (e.g., Yates et al. 2009) based on time steps of the order of hours. Nonetheless, it is important to note that these models also tend to underestimate maxima for both erosion and accretion (e.g., Splinter et al. 2014a), which can be attributed to the omission of other factors such as tides and sandbar welding to the shore.
To compare the model developed here (hereafter referred to as the RO16 model) with existing wave-driven shoreline evolution models, the model of Yates et al. (2009) is used (hereafter referred to as the YA09 model). The setup of the YA09 model is performed following the method in Castelle et al. (2014) using the calibration and simulation periods addressed herein. Results from the YA09 model are superimposed on those from the RO16 model in Fig. 7a. Consistently with the methodology described in the Materials and methods section, 

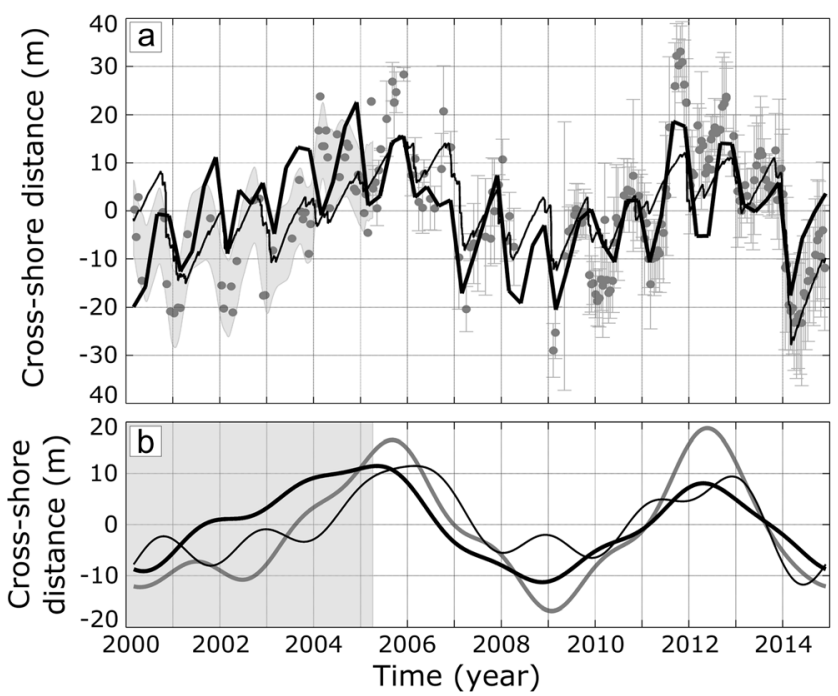

Fig. 7 a Measured (gray dots) and simulated (thick black line) shoreline position after detrending. Error bars and gray shading Alongshore variability, as in Fig. 2f. b Measured (thick gray line) and simulated (thick black line) shoreline position after detrending and 2-year low-pass filtering. Gray area Period of low-accuracy measurements. Thin black line in a and b Results obtained with the model of Yates et al. (2009) using the same calibration and simulation periods; model setup based on Castelle et al. (2014)

the new simulated shoreline position is detrended, linearly interpolated and low-pass filtered with a 2-year cutoff frequency to extract the interannual variability (Fig. 7b). Over the entire study period the interannual variability is well reproduced by the YA09 model, with a RMSE of $6.0 \mathrm{~m}$ and $R^{2}$ of 0.69 . The YA09 model does not perform better during the calibration period, as the RMSE increases to $6.4 \mathrm{~m}$ while the $R^{2}$ barely changes $(0.70)$.

The RO16 model is more skillful than the YA09 model during the calibration period presumably because of the large number of input variables and best-fit coefficients that ensure an optimized fitting with field data. Another asset of the RO16 model is that it does not need wave hindcast data, which can require much effort (e.g., model setup, computation, validation) for simulations particularly along rugged coastlines. Equilibrium shoreline models such as the YA09 model were developed to explicitly account for beach memory, which has been known for decades to be critical to short-term beach response to a given storm (Wright and Short 1984). Here, the RO16 model is successful in simulating the interannual shoreline change based on the occurrence of weather regimes without using prior weather regime conditions. This suggests that storm chronology and memory effects are much less important for interannual shoreline change than for short-term beach response.

This new modeling approach should be applicable to other North Atlantic wave-dominated beaches for which the local wave climate is modulated by large-scale atmospheric circulation adequately described by the North Atlantic weather regimes. This would require further calibration, as the best-fit coefficients are site-specific. For instance, Martínez-Asensio et al. (2016) demonstrated that while NW European Atlantic coasts experience above average wave energy conditions during high winter $\mathrm{NAO}+$, the $\mathrm{S}$ European Atlantic coasts undergo the opposite (and vice versa for high winter NAO-). This in turn drives opposite shoreline response, as for instance during the winter 2009/2010. This winter was associated with very high occurrence of the GA regime (Figs. 2a and 3e) with limited erosion at Truc Vert beach (Fig. 2f), while strong erosion was measured at Levante Beach (SW Spain; Rangel-Buitrago and Anfuso 2011). At the other end of the spectrum, beaches with similar wave exposure may exhibit similar links with weather regimes. Comparative data presented in Masselink et al. (2016a, 2016b) reveal that shoreline change patterns on interannual timescales are very similar at Perranporth beach (SW England) and Truc Vert beach. Future work should involve application of this statistical model to other coasts exposed to waves generated over the North Atlantic Ocean.

\section{Conclusions}

This paper introduces the development of a new weather regime-driven shoreline model that explains more than $70 \%$ of the shoreline interannual variability observed at a high-energy sandy beach in SW France. This implies that interannual shoreline variability on open sandy coasts can be inextricably linked to natural climatic variability over oceanic basins. Findings from this study are limited to a 15 -year shoreline time series at a given site, suggesting the need for continued or new long-term shoreline monitoring programs in contrasting hydrodynamics and geological settings to further test and improve a new generation of weather regime-driven shoreline models.

Acknowledgments This work was financially supported by the Carnot-BRGM scholarship (Carnot 2014 - Action 1) and by the Agence Nationale de la Recherche through the CHIPO project (ANR-14-ASTR0004-01). The ERA-40 and ERA-Interim reanalyses are available on the ECMWF Public Datasets web interface (http://apps.ecmwf.int/datasets/). The authors thank the colleagues, including Stephane Bujan and Sophie Ferreira, and $\mathrm{PhD}$ students involved with the topographic data collection at Truc Vert over the last 15 years. Two anonymous reviewers as well as the journal editors are gratefully acknowledged for their constructive comments and corrections that greatly improved the manuscript.

\section{Compliance with ethical standards}

Conflict of interest The authors declare that there is no conflict of interest with third parties.

Open Access This article is distributed under the terms of the Creative Commons Attribution 4.0 International License (http:// creativecommons.org/licenses/by/4.0/), which permits unrestricted use, distribution, and reproduction in any medium, provided you give appropriate credit to the original author(s) and the source, provide a link to the Creative Commons license, and indicate if changes were made. 


\section{References}

Bacon S, Carter DJT (1993) A connection between mean wave height and atmospheric pressure gradient in the North Atlantic. Int $\mathbf{J}$ Climatol 13:423-436. doi:10.1002/joc.3370130406

Barnard PL, Short AD, Harley MD and 14 others (2015) Coastal vulnerability across the Pacific dominated by El Niño/Southern Oscillation. Nat Geosci 8:801-807. doi:10.1038/ngeo2539

Barnston AG, Livezey RE (1987) Classification, seasonality and persistence of low-frequency atmospheric circulation patterns. Mon Weather Rev 115:1083-1126. doi:10.1175/1520-0493(1987)115 $<$ 1083:CSAPOL $>2.0 . \mathrm{CO} ; 2$

Barrier N, Treguier A-M, Cassou C, Deshayes J (2013) Impact of the winter North-Atlantic weather regimes on subtropical sea-surface height variability. Clim Dyn 41:1159-1171. doi:10.1007/s00382012-1578-7

Barrier N, Cassou C, Deshayes J, Treguier A-M (2014) Response of North Atlantic Ocean circulation to atmospheric weather regimes. J Phys Oceanogr 44:179-201. doi:10.1175/JPO-D-12-0217.1

Camus $\mathrm{P}$, Menéndez $\mathrm{M}$, Méndez FJ, Izaguirre $\mathrm{C}$, Espejo $\mathrm{A}$, Cánovas V, Pérez J, Rueda A, Losada IJ, Medina R (2014) A weather-type statistical downscaling framework for ocean wave climate. J Geophys Res Oceans 119:7389-7405. doi:10.1002/2014JC010141

Cassou C, Terray L, Hurrell JW, Deser C (2004) North Atlantic winter climate regimes: spatial asymmetry, stationarity with time, and oceanic forcing. J Clim 17:1055-1068. doi:10.1175/1520-0442(2004 )017<1055:NAWCRS $>2.0$. CO;2

Cassou C, Minvielle M, Terray L, Périgaud C (2011) A statistical-dynamical scheme for reconstructing ocean forcing in the Atlantic. Part I: weather regimes as predictors for ocean surface variables. Clim Dyn 36:19-39. doi:10.1007/s00382-010-0781-7

Castelle B, Marieu V, Bujan S, Ferreira S, Parisot J-P, Capo S, Sénéchal N, Chouzenoux T (2014) Equilibrium shoreline modelling of a highenergy meso-macrotidal multiple-barred beach. Mar Geol 347:8594. doi:10.1016/j.margeo.2013.11.003

Castelle B, Marieu V, Bujan S, Splinter KD, Robinet A, Sénéchal N, Ferreira S (2015) Impact of the winter 2013-2014 series of severe Western Europe storms on a double-barred sandy coast: beach and dune erosion and megacusp embayments. Geomorphology 238: 135-148. doi:10.1016/j.geomorph.2015.03.006

Charles E, Idier D, Delecluse P, Déqué M, Le Cozannet G (2012a) Climate change impact on waves in the Bay of Biscay, France. Ocean Dyn 62:831-848. doi:10.1007/s10236-012-0534-8

Charles E, Idier D, Thiébot J, Le Cozannet G, Pedreros R, Ardhuin F, Planton S (2012b) Present wave climate in the Bay of Biscay: spatiotemporal variability and trends from 1958 to 2001. J Clim 25: 2020-2039. doi:10.1175/JCLI-D-11-00086.1

Davidson MA, Turner IL (2009) A behavioral template beach profile model for predicting seasonal to interannual shoreline evolution. $\mathrm{J}$ Geophys Res 114:F01020. doi:10.1029/2007JF000888

Davidson MA, Splinter KD, Turner IL (2013) A simple equilibrium model for predicting shoreline change. Coast Eng 73:191-202. doi:10.1016/j.coastaleng.2012.11.002

Dee DP, Uppala SM, Simmons AJ and 33 others (2011) The ERA-Interim reanalysis: configuration and performance of the data assimilation system. Q J R Meteorol Soc 137:553597. doi:10.1002/qj.828

Idier D, Castelle B, Charles E, Mallet C (2013) Longshore sediment flux hindcast: spatio-temporal variability along the SW Atlantic coast of France. J Coast Res 165:1785-1790. doi:10.2112/SI65-302.1

Kuriyama Y, Banno M, Suzuki T (2012) Linkages among interannual variations of shoreline, wave and climate at Hasaki, Japan. Geophys Res Lett 39:L06604. doi:10.1029/2011GL050704
Laugel A, Menendez M, Benoit M, Mattarolo G, Méndez F (2014) Wave climate projections along the French coastline: dynamical versus statistical downscaling methods. Ocean Model 84:35-50. doi:10.1016/j.ocemod.2014.09.002

Le Cozannet G, Lecacheux S, Delvallee E, Desramaut N, Oliveros C, Pedreros R (2011) Teleconnection pattern influence on sea-wave climate in the Bay of Biscay. J Clim 24:641-652. doi:10.1175 /2010JCLI3589.1

Martínez-Asensio A, Tsimplis MN, Marcos M, Feng X, Gomis D, Jordà G, Josey SA (2016) Response of the North Atlantic wave climate to atmospheric modes of variability. Int J Climatol 36:1210-1225. doi:10.1002/joc. 4415

Masselink G, Austin M, Scott T, Poate T, Russell P (2014) Role of wave forcing, storms and NAO in outer bar dynamics on a high-energy, macro-tidal beach. Geomorphology 226:76-93. doi:10.1016/j. geomorph.2014.07.025

Masselink G, Castelle B, Scott T, Dodet G, Suanez S, Jackson D, Floc'h F (2016a) Extreme wave activity during 2013/2014 winter and morphological impacts along the Atlantic coast of Europe. Geophys Res Lett 43(2135):-2143. doi:10.1002/2015GL067492

Masselink G, Scott T, Poate T, Russell P, Davidson M, Conley D (2016b) The extreme 2013/2014 winter storms: hydrodynamic forcing and coastal response along the southwest coast of England. Earth Surf Process Landf 41:378-391. doi:10.1002 lesp.3836

Michelangeli P-A, Vautard R, Legras B (1995) Weather regimes: recurrence and quasi stationarity. J Atmos Sci 52:1237-1256. doi:10.1175/1520-0469(1995)052<1237:WRRAQS>2.0.CO;2

Rangel-Buitrago N, Anfuso G (2011) Morphological changes at Levante Beach (Cadiz, SW Spain) associated with storm events during the 2009-2010 winter season. J Coast Res 64: $1886-1890$

Ruggiero P, Komar PD, McDougal WG, Marra JJ, Beach RA (2001) Wave runup, extreme water levels and the erosion of properties backing beaches. J Coast Res 17:407-419

Sanchez-Gomez E, Somot S, Déqué M (2009) Ability of an ensemble of regional climate models to reproduce weather regimes over EuropeAtlantic during the period 1961-2000. Clim Dyn 33:723-736. doi:10.1007/s00382-008-0502-7

Serafin KA, Ruggiero P (2014) Simulating extreme total water levels using a time-dependent, extreme value approach. J Geophys Res Oceans 119:6305-6329. doi:10.1002/2014JC010093

Silva AN, Taborda R, Bertin X, Dodet G (2012) Seasonal to decadal variability of longshore sand transport at the northwest coast of Portugal. J Waterw Port Coast Ocean Eng 138:464-472. doi:10.1061/(ASCE)WW.1943-5460.0000152

Splinter KD, Turner IL, Davidson MA, Barnard P, Castelle B, OltmanShay J (2014a) A generalized equilibrium model for predicting daily to interannual shoreline response. J Geophys Res Earth Surf 119: 1936-1958. doi:10.1002/2014JF003106

Splinter KD, Carley JT, Golshani A, Tomlinson R (2014b) A relationship to describe the cumulative impact of storm clusters on beach erosion. Coast Eng 83:49-55. doi:10.1016/j. coastaleng.2013.10.001

Stive MJF, Aarninkhof SGJ, Hamm L, Hanson H, Larson M, Wijnberg KM, Nicholls RJ, Capobianco M (2002) Variability of shore and shoreline evolution. Coast Eng 47:211-235. doi:10.1016/S03783839(02)00126-6

Ullmann A, Monbaliu J (2010) Changes in atmospheric circulation over the North Atlantic and sea-surge variations along the Belgian coast during the twentieth century. Int J Climatol 30:558-568. doi:10.1002/joc. 1904

Ullmann A, Moron V (2008) Weather regimes and sea surge variations over the Gulf of Lions (French Mediterranean coast) during the 20th century. Int J Climatol 28:159-171. doi:10.1002/joc.1527 
Uppala SM, Kållberg PW, Simmons AJ and 43 others (2005) The ERA-40 re-analysis. Q J R Meteorol Soc 131:2961-3012. doi:10.1256/qj.04.176

Vautard R (1990) Multiple weather regimes over the North Atlantic: analysis of precursors and successors. Mon Weather Rev 118: 2056-2081. doi:10.1175/1520-0493(1990)118<2056 :MWROTN>2.0.CO;2

Woolf DK, Challenor PG, Cotton PD (2002) Variability and predictability of the North Atlantic wave climate. J Geophys Res 107:9-1-9-14. doi:10.1029/2001JC001124
Wright L, Short A (1984) Morphodynamic variability of surf zones and beaches: a synthesis. Mar Geol 56:93-118. doi:10.1016/0025-3227 (84)90008-2

Yates ML, Guza RT, O’Reilly WC (2009) Equilibrium shoreline response: observations and modeling. J Geophys Res 114:C09014. doi:10.1029/2009JC005359

Young IR (1999) Seasonal variability of the global ocean wind and wave climate. Int J Climatol 19:931-950. doi:10.1002/(SICI)1097-0088 (199907)19:9<931::AID-JOC412>3.0.CO;2-O 